\title{
Observation of ozone enhancement in the lower troposphere over East Asia from a space-borne ultraviolet spectrometer
}

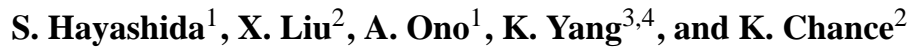 \\ ${ }^{1}$ Faculty of Science, Nara Women's University, Nara 630-8263, Japan \\ ${ }^{2}$ Harvard-Smithsonian Center for Astrophysics, Cambridge, Massachusetts 02138, USA \\ ${ }^{3}$ Department of Atmospheric and Oceanic Science, University of Maryland College Park, Maryland 20742, USA \\ ${ }^{4}$ NASA Goddard Space Flight Center, Greenbelt, Maryland 20771, USA \\ Correspondence to: S. Hayashida (sachiko@ics.nara-wu.ac.jp)
}

Received: 13 November 2014 - Published in Atmos. Chem. Phys. Discuss.: 22 January 2015

Revised: 3 July 2015 - Accepted: 18 August 2015 - Published: 2 September 2015

\begin{abstract}
We report observations from space using ultraviolet (UV) radiance for significant enhancement of ozone in the lower troposphere over central and eastern China (CEC). The recent retrieval products of the Ozone Monitoring Instrument (OMI) onboard the Earth Observing System (EOS) Aura satellite revealed the spatial and temporal variation of ozone distributions in multiple layers in the troposphere. We compared the OMI-derived ozone over Beijing with airborne measurements by the Measurement of Ozone and Water Vapor by Airbus In-Service Aircraft (MOZAIC) program. The correlation between OMI and MOZAIC ozone in the lower troposphere was reasonable, which assured the reliability of OMI ozone retrievals in the lower troposphere under enhanced ozone conditions. The ozone enhancement was clearly observed over CEC, with Shandong Province as its center, and was most notable in June in any given year. Similar seasonal variations were observed throughout the 9-year OMI measurement period of 2005 to 2013. A considerable part of this ozone enhancement could be attributed to the emissions of ozone precursors from industrial activities and automobiles, and possibly from open crop residue burning (OCRB) after the winter wheat harvest. The ozone distribution presented in this study is also consistent with some model studies. The lower tropospheric ozone distribution is first shown from OMI retrieval in this study, and the results will be useful in clarifying any unknown factors that influence ozone distribution by comparison with model simulations.
\end{abstract}

\section{Introduction}

Ozone in the atmospheric boundary layer is produced by chemical reactions between nitrogen oxides $\left(\mathrm{NO}_{x}\right)$ and volatile organic compounds (VOCs) in the presence of sunlight. Anthropogenic activities contribute to atmospheric concentrations of $\mathrm{NO}_{x}$ and VOCs, and the resulting boundary layer ozone has harmful effects on plant growth and human health. The ozone produced in the boundary layer is transported to the free troposphere and is dispersed globally. Since ozone absorbs the Earth's radiation, increased ozone contributes to global warming. In the Fourth Assessment Report of the Intergovernmental Panel on Climate Change (IPCC AR4; IPCC, 2007), the contribution of the tropospheric ozone increase after the Industrial Revolution to global warming was estimated to be 0.25 to $0.65 \mathrm{~W} \mathrm{~m}^{-2}$ in terms of radiative forcing for the years 1750 to 2005 .

In recent years, ozone pollution has become a serious environmental problem in megacities around the world, and the hazardous air pollution over large cities in China is particularly concerning. Thus far, many studies conducted with ground-based measurements have reported significant enhancements in ozone concentrations near the surface over Beijing (e.g., Wang et al., 2006) and the North China Plain (e.g., Lin et al., 2008; Ding et al., 2013). Emissions of ozone precursors from industrial activities and automobile exhaust have been examined to understand the air pollution over China, and a comprehensive bottom-up emission inventory has been developed (Streets et al., 2003; Ohara et al., 2007). However, recent studies have shown that agricultural activ- 
ities such as open crop residue burning (OCRB) may also have a significant effect on ozone pollution over the North China Plain (Fu et al., 2007; Kanaya et al., 2013). The inclusion of OCRB in the bottom-up inventory is currently a major research topic (Yamaji et al., 2010), although emissions of ozone precursors from agricultural activities have been difficult to quantify. Direct ozone monitoring can yield more important information than that derived from the indirect monitoring of ozone precursors to evaluate the actual extent of ozone pollution. However, the surface ozone-monitoring network in China is not sufficiently developed. Additionally, the frequent photochemical smog events in Japan and South Korea in recent years are regarded as being at least partly due to the transport of transboundary ozone pollution from China. Monitoring of transboundary ozone pollution in East Asia by only ground-based monitoring stations and sea-borne measurements will likely be insufficient for resolving these issues.

Given this background, satellite measurements may play an increasingly important role in ozone monitoring over large areas of land and ocean. Many studies have previously reported space-borne measurements of air pollution over China. Richter et al. (2005) found a highly significant increase in $\mathrm{NO}_{2}$ over industrial areas of China by using the Global Ozone Monitoring Experiment (GOME) onboard the European Remote Sensing Satellite (ERS-2). Chance et al. (2000) succeeded in retrieving formaldehyde (HCHO) from GOME spectra, and long-term data have been accumulated. Fu et al. (2007) reported on the enhancements of HCHO over East and South Asia and investigated the effects of biomass burning on ozone production. Since then, $\mathrm{NO}_{2}$ and $\mathrm{HCHO}$ distributions over China have been observed by satellite sensors such as the Scanning Imaging Absorption Spectrometer for Atmospheric Chartography (SCIAMACHY; e.g., Gottwald and Bovensmann, 2011), the Ozone Monitoring Instrument (OMI; Levelt et al., 2006), and GOME-2 (EUMETSAT, 2006). Although these satellite data are highly valuable, it should be noted that satellite measurements using backscattered sunlight as a light source mostly give information on column abundance. Although ozone precursors such as $\mathrm{NO}_{2}$ and VOCs can be estimated from space with reasonable accuracy, they are most abundant in the lower troposphere. However, only limited satellite observations of ozone in the lowermost troposphere have been reported.

The amount of ozone in the boundary layer is usually only several percentage points of the total amount; $90 \%$ of the total ozone is in the stratosphere and approximately $10 \%$ is in the troposphere. Therefore, the vertical discrimination of ozone in the lower troposphere has posed a significant challenge in satellite-borne measurement. However, substantial progress has been made on this difficult problem. Historically, observations of atmospheric ozone began with measurements of the ultraviolet (UV) spectrum, most notably with the Dobson spectrometer. Satellite sensors in- tended for ozone measurements were developed by following the heritage of ground-based instruments. The first spaceborne sensor for ozone measurements with daily global coverage was the Total Ozone Mapping Spectrometer (TOMS) onboard the Nimbus-7 satellite, which produced daily global maps of the total ozone column from 1978 to 1993 . The succeeding TOMS sensors onboard Meteor-3, the Advanced Earth Observing Satellite (ADEOS), and Earth Probe (EP)TOMS provided long-term records of the global total ozone. The first space-based measurements of tropospheric column ozone (TCO) were derived by subtracting the stratospheric column ozone (SCO) from the total ozone obtained by TOMS, which is known as the tropospheric ozone residual (TOR) method (Fishman and Larsen, 1987). The SCO was obtained from other sensors such as SAGE-II or climatology data. Fishman et al. (2003) noted a correlation when comparing the TCO derived from the TOR method with the population distribution. Kar et al. (2010) also analyzed TCO and found enhancements near several large polluted cities such as Beijing, New York, Sao Paulo, and Mexico City. Importantly, these previous studies demonstrated the potential of measuring ozone enhancements in the lower troposphere from satellite observations of UV spectra.

We have studied tropospheric ozone over East Asia for the past several decades and have archived ozone data from ozonesondes, airborne sensors, and satellite sensors. Hayashida et al. (2008) reported an enhanced tropospheric column ozone (E-TCO) belt over East Asia by analysis of TCO obtained from GOME (Liu et al., 2005) with ozonesonde measurements. Nakatani et al. (2012) analyzed the E-TCO belt in detail and reported that the belt is closely related to the intrusion of stratospheric ozone near the location of the subtropical jet (STJ). Ozone-enhanced regions over large East Asian cities are often situated near the STJ. As shown in our previous studies, the following issues must be addressed: (1) tropospheric ozone can vary greatly, according to stratospheric ozone intrusion near the STJ, and (2) the retrieval scheme for satellite data includes large smoothing errors. Therefore, the retrieved ozone enhancement signal in the lower troposphere can be caused by actual ozone enhancement in the upper troposphere, and actual ozone enhancement in the lower troposphere is retrieved in a broader vertical range. Regarding issue (1), the enhancement of TCO does not necessarily indicate increased ozone production in the lower troposphere; the enhancement may be related to intrusion of stratospheric ozone. Regarding issue (2), the satellites detect ozone enhancement signals in the middle or upper troposphere as well as in the lower troposphere, where actual ozone enhancement occurs. However, as shown in Fig. 5 of Nakatani et al. (2012), TCO enhancement was unquestionably detected over Shandong, away from the location of the STJ. As this example shows, it is possible to detect lower tropospheric ozone enhancement by careful analysis of the STJ location from meteorological data as well as ozone data with the inclusion of a full uncertainty analysis. 
The sensitivity of satellite measurements to ozone in the troposphere is dependent on the spectral region of the measurements, and the amount and height of the ozone. UV radiation generally has a higher sensitivity to ozone in the lowermost altitudes than thermal infrared (TIR) radiation, whereas thermal radiation has a higher sensitivity to ozone in the middle and upper troposphere (Natraj et al., 2011). Therefore, the combined use of radiation from different wavelength regions can improve the sensitivity of measurements to ozone in the lower troposphere. Recently, some studies have shown synergistic schemes to derive ozone profiles in the troposphere by combining UV and TIR radiation (Worden et al., 2007; Landgraf and Hasekamp, 2007; Cuesta et al., 2013; Fu et al., 2013). Those studies demonstrated that the synergistic schemes allow for significant improvement of vertical ozone profiling in the troposphere.

On the other hand, Liu et al. (2010a) developed an algorithm for retrieving ozone profiles from the ground to an altitude of $\sim 60 \mathrm{~km}$ from only OMI UV radiances using the optimal estimation technique (Rogers, 2000). This algorithm derives the ozone profile by dividing it into 24 layers, with about 3-7 layers in the troposphere. Although it is generally difficult to distinguish ozone in the boundary layer from mid-tropospheric ozone, this algorithm can provide some information on the relative variation of ozone in the boundary layer under highly enhanced ozone conditions such as those that occur over central and eastern China (CEC). Moreover, significant information can be obtained from the retrievals when accumulated in large numbers.

In this study, we present results of the analysis of lower tropospheric ozone over CEC on the basis of OMI ozone profiles derived from UV radiances. In Sect. 2, we describe the details of the data used in the analysis. In Sect. 3, we show the ozone retrievals, introduce subsequent analyses, and discuss the uncertainties involved with ozone retrieval from UV spectra and the possible effects of OCRB on ozone enhancement. In addition, we recommend areas for future research in Sect. 4.

\section{Data and methodology}

\subsection{Ozone profile data derived from OMI}

OMI is a Dutch-Finnish-built nadir-viewing pushbroom UV/visible instrument carried on the National Aeronautics and Space Administration's (NASA's) EOS Aura spacecraft in a Sun-synchronous orbit with an equatorial crossing time of $\sim 13: 45$ local time (LT). The instrument measures backscattered radiances in three channels covering a wavelength range of 270 to $500 \mathrm{~nm}$ (UV-1: 270 to $310 \mathrm{~nm}$; UV-2: 310 to $365 \mathrm{~nm}$; visible: 350 to $500 \mathrm{~nm}$ ) at a spectral resolution of 0.42 to $0.63 \mathrm{~nm}$ (Levelt et al., 2006). OMI has daily global coverage with a spatial resolution of $13 \times 24 \mathrm{~km}^{2}$ (along and across track) at the nadir position for UV-2 and visible channels, and $13 \times 48 \mathrm{~km}^{2}$ for the UV-1 channel.

Recently, Liu et al. (2010a) developed a new retrieval algorithm for OMI based on that initially developed for GOME (Liu et al., 2005) by using the optimal estimation technique (Rodgers, 2000). They retrieved ozone profiles from the ground upward to about $60 \mathrm{~km}$ in 24 layers, of which layers 3-7 are in the troposphere. The lowermost layer, the 24th layer, corresponds to a layer from $0 \mathrm{~km}$ to about $3 \mathrm{~km}$ above the surface. The 23rd and 22nd layers correspond to those about 3 to $6 \mathrm{~km}$ and 6 to $8 \mathrm{~km}$ in altitude, respectively. However, there is a wide variety of altitude boundaries for these layers, depending on meteorological conditions. To constrain the retrievals, Liu et al. (2010a) used climatological mean ozone profiles and standard deviations derived from 15 years of ozonesonde measurements and the Stratospheric Aerosol and Gas Experiment (SAGE) as a priori, which varied with latitude and month (McPeters et al., 2007). Several modifications have been made in producing the ozone profile product used in this study, as described by Kim et al. (2013). The retrieval was performed here at a nadir resolution of $52 \mathrm{~km} \times 48 \mathrm{~km}$ by co-adding $4 / 8 \mathrm{UV} 1 / \mathrm{UV} 2$ pixels to increase the processing speed. In addition, a minimum measurement error of $0.2 \%$ has been imposed in the spectral region of 300 to $330 \mathrm{~nm}$ to stabilize the retrievals, although this inclusion also significantly reduced the retrieval sensitivity to lower tropospheric ozone reflected in the retrieval averaging kernels (AKs) compared with those reported by Liu et al. (2010a). However, the reported retrieval sensitivity to tropospheric ozone might be underestimated, because the relative fitting residuals in UV2 $(310-330 \mathrm{~nm})$ are generally significantly smaller than $0.2 \%$ and can be as low as $0.06 \%$, except for solar zenith angles greater than $60^{\circ}$. The capability to discriminate the vertical distribution of ozone profiles from backscattered UV measurements in the Hartley and Huggins bands arises primarily from wavelength-dependent photon penetration resulting from wavelength-dependent ozone absorption and its interaction with Rayleigh scattering (Bhartia et al., 1996). Vertical sensitivity to ozone in the troposphere, although much smaller compared to that in the stratosphere, arises from wavelengths longer than $\sim 300 \mathrm{~nm}$. Temperaturedependent ozone absorption in the Huggins bands provides additional tropospheric ozone information (Chance et al., 1997). The distribution of vertical sensitivity depends on the retrieval spectral range, measurement signal-to-noise ratio, fitting quality, viewing geometry, cloudiness, surface albedo, and the vertical distribution of ozone.

Here, we show the analysis based on the Level 3 products that are gridded to $1^{\circ} \times 1^{\circ}$ (latitude $\times$ longitude) spatial resolution on a daily basis. The quality of OMI measurements has been impacted by the row anomaly (http://www.knmi.nl/ omi/research/product/rowanomaly-background.php) that became significant in January 2009, affecting more than onethird of the across-track OMI pixels. OMI pixels affected by the row anomaly were not used in the gridding. The gridded 
data were screened by the criteria of effective cloud fraction (ECF) $<0.2$ and RMS (defined as the root mean square of the ratio of the fitting residual to the assumed measurement error of the UV2 channel) $<2.4$. The RMS values of OMI retrievals increased with time, especially after 2008. In addition, OMI lost significant spatial coverage owing to the row anomaly. A relaxed RMS threshold of 2.4 was used throughout the measurement period to obtain sufficient OMI data for analysis after 2008. Although a stricter threshold was applicable for the period before 2008, this relaxation did not affect data selection because the RMS of most of the data was much smaller $(\lesssim 1.5)$ for data before 2008 (Fig. S.1 in the Supplement).

Because the a priori data were taken from climatology and were dependent on latitude and month, seasonal variation must be considered. To follow the temporal evolution of the ozone concentration, we analyzed the anomaly of ozone $\left(\Delta \mathrm{O}_{3}\right)$, which is defined as the difference from the a priori values $\left(\Delta \mathrm{O}_{3}=\mathrm{O}_{3}\right.$ [retrieval] $-\mathrm{O}_{3}$ [a priori]). The $\Delta \mathrm{O}_{3}$ value can be interpreted as an indicator of the ozone variation from OMI measurements regardless of a priori data. It should be noted that the climatological a priori data do not include any significant longitudinal pattern over the regions of focus in this study, although the a priori ozone shows some slight longitudinal variation due to variations in surface and tropopause pressure and thus the thickness of the layer.

\subsection{Airborne measurements and ozonesonde measurements over Beijing}

The Measurement of Ozone and Water Vapor by Airbus InService Aircraft (MOZAIC) program was initiated in 1993 by European scientists, aircraft manufacturers, and airlines to collect experimental data (Marenco et al., 1998). Ozone profiles are obtained during the ascent and descent of aircraft over major cities. Over Beijing, data are available from March 1994 to November 2005 (http://www.meteo.fr/cic/ meetings/2014/MOZAIC-IAGOS/), and we have archived all profiles. In this study, we used the MOZAIC ozone profiles obtained in 2004 and 2005 to validate the OMI retrieval product in the lower troposphere.

\subsection{Meteorological data (NCEP)}

Meteorological reanalysis data provided by the National Centers for Environmental Prediction (NCEP; http://www. esrl.noaa.gov/psd/data/gridded/data.ncep.reanalysis.html) were used to investigate the meteorological conditions. Pressure height and wind data were utilized to determine the subtropical jet location.

\subsection{Hotspots}

The biomass burnings detected by satellite observations are expressed as hotspot numbers. Here, we used the hotspot numbers from the global Moderate Resolution Imaging
Spectroradiometer (MODIS) Collection 5 active fire product (MCD14ML) as a proxy for the fire detection index. The MODIS fire detection algorithm detects fires by applying thresholds to the brightness temperatures observed in the middle and TIR regions (Justice et al., 2002; Giglio et al., 2003). The MCD14ML global data set was downloaded from the FTP server at the University of Maryland (ftp://fuoco.geog.umd.edu/). The hotspot products include information on date, time, satellite name, latitude, longitude, temperature in channel 21 , temperature in channel 32 , sensor sample number, fire radiative power (FRP), and confidence level. In this study, we selected data in which the detection confidence level was greater than $80 \%$.

\subsection{Carbon monoxide: measurements of pollution in the troposphere}

Carbon monoxide (CO) data were taken from the Measurements of Pollution in the Troposphere (MOPITT) instrument carried by NASA's EOS Terra spacecraft in a Sunsynchronous orbit with an equatorial crossing time of about 10:30. MOPITT operates by sensing infrared radiation either from thermal emission/absorption at $4.7 \mu \mathrm{m}$ for $\mathrm{CO}$ profiles, or from reflected sunlight at about $2.2-2.4 \mu \mathrm{m}$ for $\mathrm{CO}$ column measurements in daylight. The use of solar channels enhances the instrument's sensitivity to the atmospheric boundary layer (https://www2.acd.ucar.edu/mopitt/concepts). MOPITT has been operational since March 2000. We used the total column amount of daytime in the Version 6 Level 3 thermal infrared/near-infrared (TIR/NIR) multispectral products (Deeter et al., 2011, 2013), which is referred to as "RetrievedCOTotalColumnDay" in this study.

\section{Results and discussion}

\subsection{Comparison of OMI-retrieved ozone at the lower troposphere with MOZAIC measurements}

In this section, we compare the OMI-retrieved ozone data with MOZAIC airborne data. Because the MOZAIC ozone profiles are limited to below $\sim 9 \mathrm{~km}$, the OMI data corresponding to the 22nd layer (about 6 to $8 \mathrm{~km}$ ), the 23rd layer (about 3 to $6 \mathrm{~km}$ ), and the 24th layer (about 0 to $3 \mathrm{~km}$ ) are comparable to MOZAIC measurements. Therefore, this section focuses on these layers.

\subsubsection{Climatology of ozone profiles over Beijing observed by MOZAIC airborne measurements}

Ozone profiles over Beijing have been obtained by MOZAIC airborne measurements taken from March 1995 through November 2005. We fully analyzed the ozone profiles over Beijing for the entire period, and here we present the data in 2004 and 2005 when OMI data are also available. Figure 1a shows the daily values of the ozone mixing ratio 
(in ppbv) observed by MOZAIC measurements over Beijing in 2004 and 2005, and Fig. 1b shows their monthly mean values. For most days, measurements were conducted twice daily; the daily averaged values for the two measurements are shown in Fig. 1a. The number of data used for each month is shown in Fig. 1b. Some profiles do not cover all altitudes, as shown in the figure; thus, the number of data depended on altitude for some months. Above $6 \mathrm{~km}$ in altitude, the mixing ratio was often as high as 80 to $100 \mathrm{ppbv}$, as shown in July 2005, which clearly indicates the effects of stratospheric ozone intrusion. During the period of March 1995 to November 2005, we found that the effects of ozone intrusion from the stratosphere were sometimes remarkable over Beijing. Ozonesonde measurements revealed similar features over Sapporo and Tsukuba in winter and early spring every year (Nakatani et al., 2012). In June 2005, enhancement of the lower tropospheric ozone $(<2 \mathrm{~km})$ was remarkable. Because the minimum ozone mixing ratio was also clearly detected at around $4 \mathrm{~km}$ in altitude, we concluded that enhancement of the lower tropospheric ozone was not connected to stratospheric ozone intrusion into the lower troposphere. Rather, the ozone enhancement can be regarded as being derived from ozone production in the lower troposphere. A typical example is shown in greater detail in the following section.

\subsubsection{A typical example of significant enhancement of lower tropospheric ozone observed on 22 June 2005}

Figure 2 depicts the MOZAIC ozone profile obtained at $14: 18$ LT on 22 June 2005 , which is close to the time of the OMI observation at 13:45. A significant enhancement of ozone was observed on that day. The ozone in the boundary layer as observed at 10:41 was about $120 \mathrm{ppbv}$ and increased to about $190 \mathrm{ppbv}$ at the peak altitude at $14: 18$. The profiles of $\mathrm{CO}, \mathrm{H}_{2} \mathrm{O}$, and temperature are also shown with the ozone profile in the figure. A CO enhancement of up to $1 \mathrm{ppmv}$ is also clearly visible in the figure, corresponding to ozone enhancement in the boundary layer $(<2 \mathrm{~km})$. However, there was no sign of tropopause folding in the temperature and $\mathrm{H}_{2} \mathrm{O}$ profiles on that day. These measurements clearly indicate that the enhancement of ozone at a lower altitude $(<2 \mathrm{~km})$ is not attributable to intrusion of stratospheric ozone, but rather to ozone production in the boundary layer.

In Fig. 2, OMI-derived ozone data for the three layers (22nd, 23rd, and 24th) in the troposphere are also shown with the a priori data. For comparison with the coarseresolution OMI data, the MOZAIC ozone profile, which originally had a $150 \mathrm{~m}$ resolution, was averaged for the corresponding layers. In the 24th layer, the OMI retrieval was significantly lower than the corresponding smoothed-MOZAIC ozone value, but was higher than the a priori value. In the upper two layers, OMI retrievals did not differ significantly from the smoothed-MOZAIC ozone values. In the following

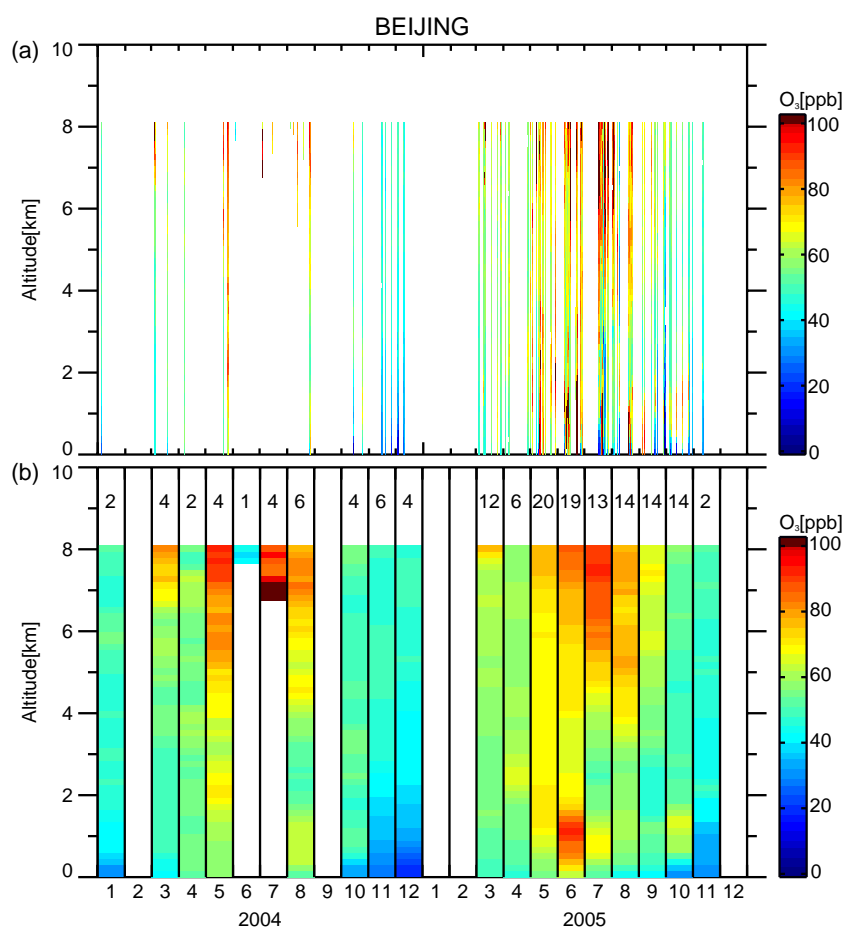

Figure 1. (a) Time-altitude cross section of daily mean ozone mixing ratios observed by MOZAIC over Beijing in 2004 and 2005. Two measurements were conducted on most days. Daily values are the average of the two data sets obtained on the same day. (b) Same as (a) but for monthly mean ozone mixing ratios. The number of data used in the analysis for each month are shown.

section, we compare the OMI retrievals with MOZAIC measurements obtained in 2004 and 2005 in greater detail.

\subsubsection{Validation of OMI-derived ozone by MOZAIC measurements}

We selected the OMI data at the grid including Beijing from the same day as the MOZAIC measurements were conducted. As described in Sect. 2, all OMI data were prescreened by the criteria of ECF and RMS. When multiple data were available on the same day, we selected the data closer to 13:45. Finally, we chose 36 profiles in 2004 and 2005, which are listed in Table 1. To compare the OMI and MOZAIC ozone data, we accumulated the MOZAIC data of about $150 \mathrm{~m}$ resolution to adjust to the coarse OMI-retrieved ozone layers.

The leftmost panels in Fig. 3 depict correlations between the smoothed-MOZAIC ozone data and OMI-derived ozone data in Dobson units (DU). The three panels represent the 22nd, 23rd, and 24th layers, respectively. The linear regression equation of best fit is shown above each panel with a coefficient of determination, known as the $R^{2}$ value. Although OMI ozone retrievals considerably underestimate ozone concentrations, a good linearity was recognized because the $R^{2}$ 


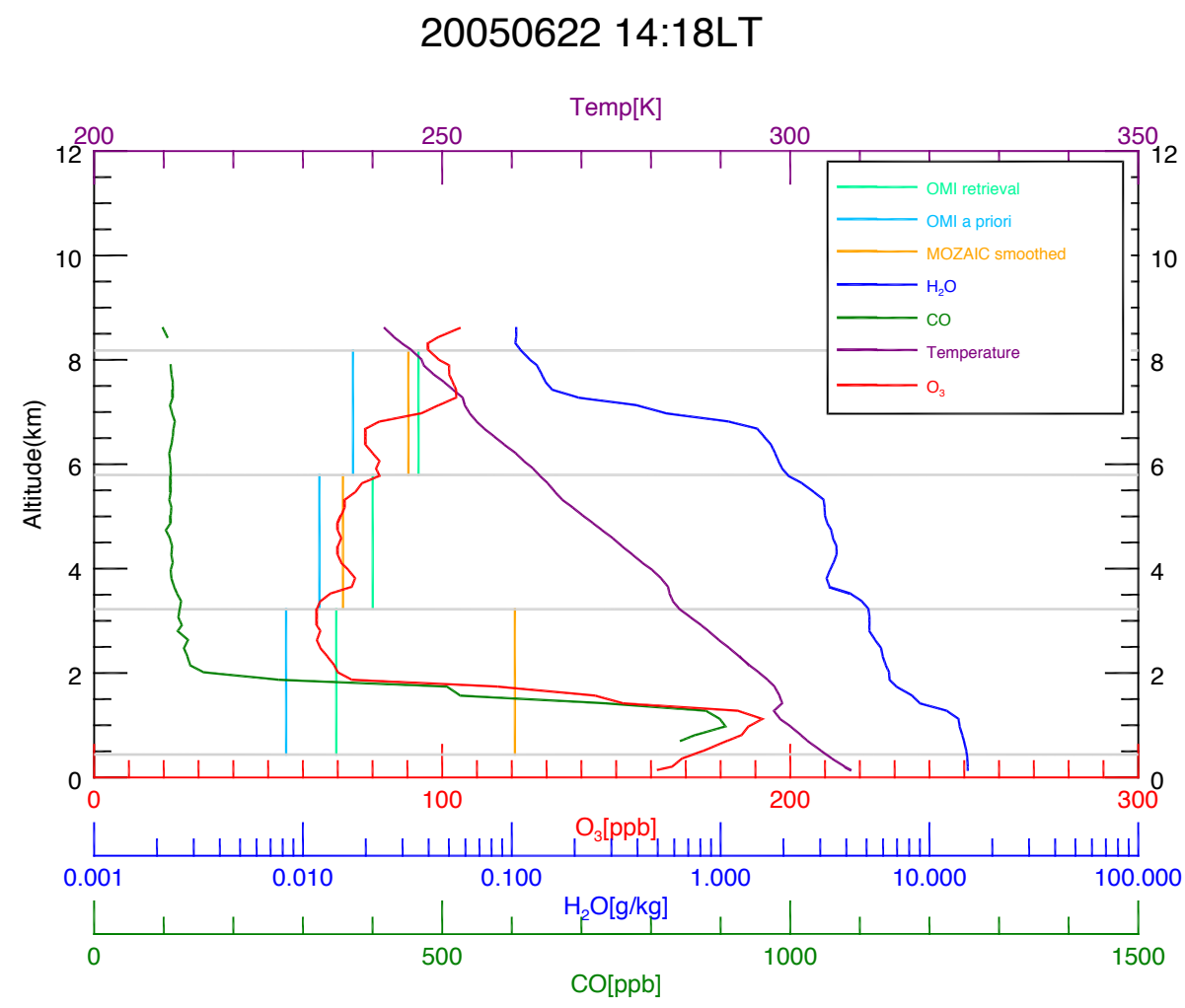

Figure 2. Vertical profiles of ozone (red), $\mathrm{CO}$ (green), $\mathrm{H}_{2} \mathrm{O}$ (blue), and temperature (purple) obtained by MOZAIC airborne measurements on 22 June 2005 at 14:18 LT over Beijing. The scale of each parameter is shown in the same colors. The smoothed-MOZAIC ozone profile according to the corresponding OMI layers is shown by orange lines. Correspondingly, a priori and OMI-retrieved ozone are shown in light blue and light green, respectively. The OMI 22nd, 23rd, and 24th layers correspond to 6-8, 3-6, and 0-3 km, respectively.

values were as large as 0.68 at the 24th layer. Good correlation was present partly because the a priori data implicitly involve seasonal variation. The data shown in Fig. 3 are color coded according to month; seasonal variations with highs during the summer and lows in winter are notable in both the MOZAIC ozone data and OMI retrievals. To avoid this effect on evaluation of the correlation, we also show correlations between the differences from the a priori values. Here, we denote MOZAIC ozone as $X$ and the a priori data as $X_{a}$. The $\Delta \mathrm{O}_{3}$ of $\mathrm{OMI}$ is defined as $\mathrm{O}_{3}$ (retrieval) $-X_{a}$, as mentioned in Sect. 2. The three panels in the middle of Fig. 3 show correlation between $X-X_{a}$ (MOZAIC) and $\Delta \mathrm{O}_{3}$ (OMI). The values of $\Delta \mathrm{O}_{3}$ (OMI) follow the large variability of $X-X_{a}$ (MOZAIC) with good linearity, reflecting frequent enhancements of ozone in the 24th layer. In contrast, correlations were weaker in the other two layers because the variations of $X-X_{a}$ (MOZAIC) in those layers were significantly smaller than those in the 24th layer.

At the 24th layer, the $R^{2}$ value was as large as 0.47 , and the linearity of $\Delta \mathrm{O}_{3}$ with $X-X_{a}$ can be used as an indicator of relative changes in ozone in the lower troposphere. In terms of absolute values, the OMI retrievals at the same layer significantly underestimated the ozone: the regression coefficient for OMI vs. MOZAIC ozone was 0.17. To understand the underestimation of the OMI-observed ozone, we need to examine the large smoothing error in the OMI retrievals. To this end, we examine AKs in detail in the following section.

\subsubsection{Sensitivity of the OMI ozone retrieval scheme to the lower troposphere}

Figure 4 shows the AKs at the grid including Beijing on 22 June 2005. The profiles of the a priori and OMI-retrieved ozone are shown in the left panel. The middle panel shows profiles of the rows of AKs that are normalized by the a priori error (Liu et al., 2010a) for the six layers (layers 1924) of OMI retrieval. The right panel shows similar profiles but presents the columns of AKs. The rows and columns of AKs for each layer indicate the sensitivity of retrieved ozone at this layer to the actual ozone change at all layers and the sensitivity of retrieved ozone at all layers to the actual ozone change at this layer, respectively. The total retrieval efficiency shown in parentheses in the legend is defined as the sum of the column of AKs for each layer. The total retrieval efficiency at a specific layer indicates the fraction of the actual ozone change at the layer that is retrieved at all layers. Liu et al. (2010a) reported that although the tropospheric degree of freedom for the signal (DFS) for clear-sky con- 

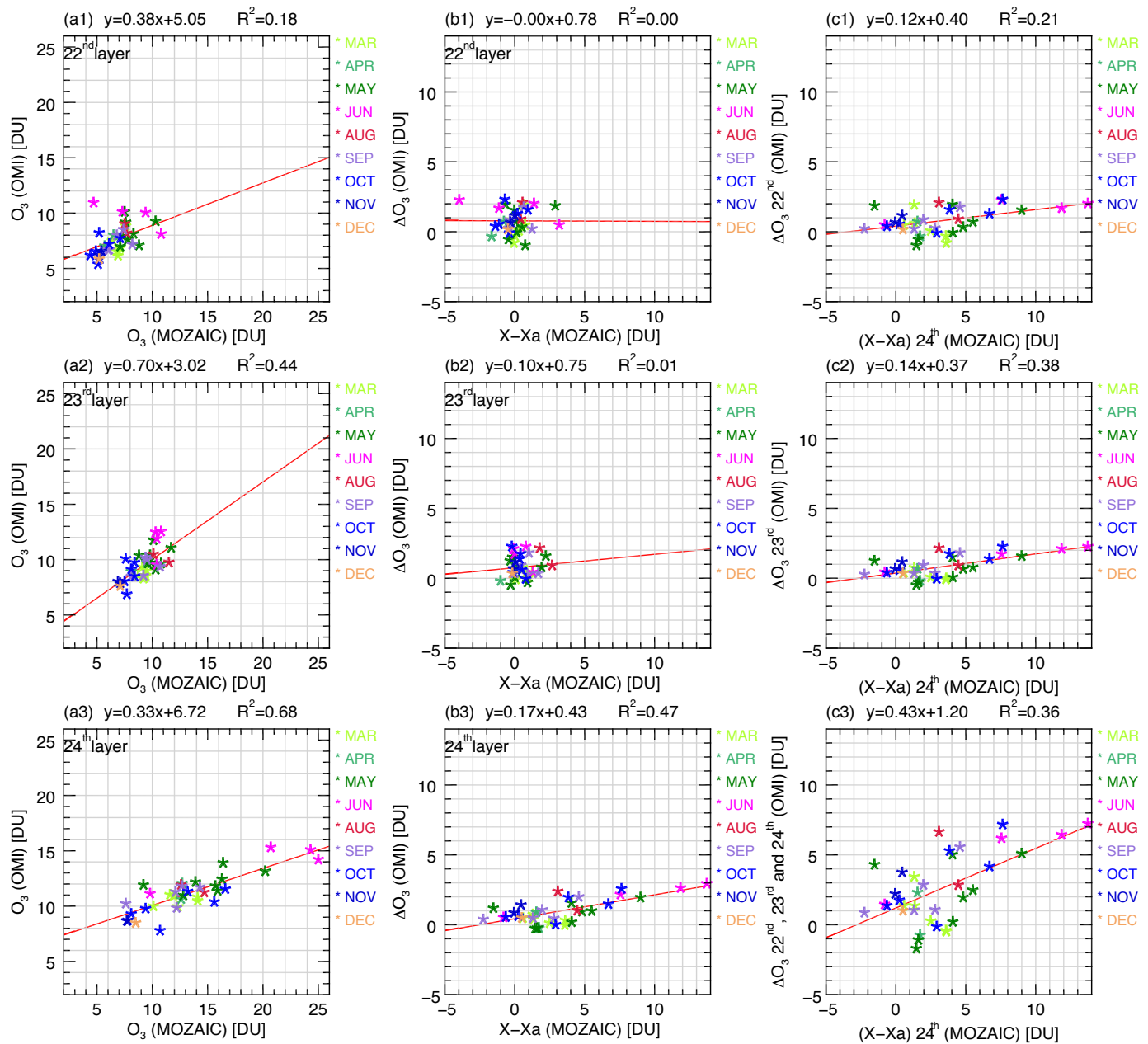

Figure 3. (Left) Direct correlation of MOZAIC ozone data (averaged to adjust for OMI height resolution) and OMI ozone retrievals at the (a1) 22nd, (a2) 23rd, and (a3) 24th layers for the coincident 36 days in 2004 and 2005. (Middle) Same as leftmost panels but for the differences from a priori values: $X-X_{a}$ taken from MOZAIC; $\Delta \mathrm{O}_{3}$ taken from OMI. (1), (2), and (3) represent the 22nd, 23rd, and 24th layers, respectively, for each panel. (Right) Same as in the middle panels except that for (c1) $X-X_{a}$ taken from MOZAIC at the 24th layer and $\Delta \mathrm{O}_{3}$ from OMI at the 22nd layer, (c2) $X-X_{a}$ taken from MOZAIC at the 24th layer and $\Delta \mathrm{O}_{3}$ taken from OMI at the 23rd layer, and (c3) $X-X_{a}$ taken from MOZAIC at the 24th layer and the summation of $\Delta \mathrm{O}_{3}$ taken from OMI at layers 22 to 24 . The linear regression equation and coefficient of determination, or $R^{2}$ values, are shown above each panel. All data are color coded according to month. The 36-day data used in the analysis are listed in Table 1.

ditions typically peaks in the $500-700 \mathrm{hPa}$ layer (i.e., layer 23) and that the DFS in the lower troposphere is generally small, the retrieval efficiency for the lowermost layer is typically $0.4-0.7$ for most tropical and mid-latitude summer conditions owing to the small solar zenith angles. This indicates that $40-70 \%$ of the actual ozone change from the a priori in the 24th layer can be retrieved, although not necessarily at the same layer due to smoothing. For the grid including Beijing, shown in Fig. 4, the DFS for layer 24 was only 0.11 . However, the rows of AKs (middle panel) show a small peak at layer 24 and the total retrieval efficiency for layer 24 was 0.46 ; i.e., almost $50 \%$ of the ozone enhancement from the lowermost layer can be retrieved. The columns of AKs indicate that the retrieval response to the actual enhancement of ozone at the 24th layer does not necessarily peak at the 24th layer, but may also peak at the upper layers. However, the enhancement of ozone in the upper troposphere, such as in the 21 st or 22 nd layer, does not lead to a peak at the 23rd or 24th layer. Therefore, identification of the layer of the peak ozone enhancement in the OMI retrieval is useful for distinguishing the cause of ozone enhancement.

In the rightmost panels of Fig. 3, we show the correlation between $X-X_{a}$ (MOZAIC) at the 24th layer and the $\Delta \mathrm{O}_{3}$ (OMI) of the 22nd layer (c1), or the $\Delta \mathrm{O}_{3}$ (OMI) of the 23rd layer (c2). In the 22nd and 23rd layers, the variation in ozone quantities observed by MOZAIC was less than that in the 24th layer. Thus, the correlation between MOZAIC and OMI was unclear; the ozone data were scattered almost 


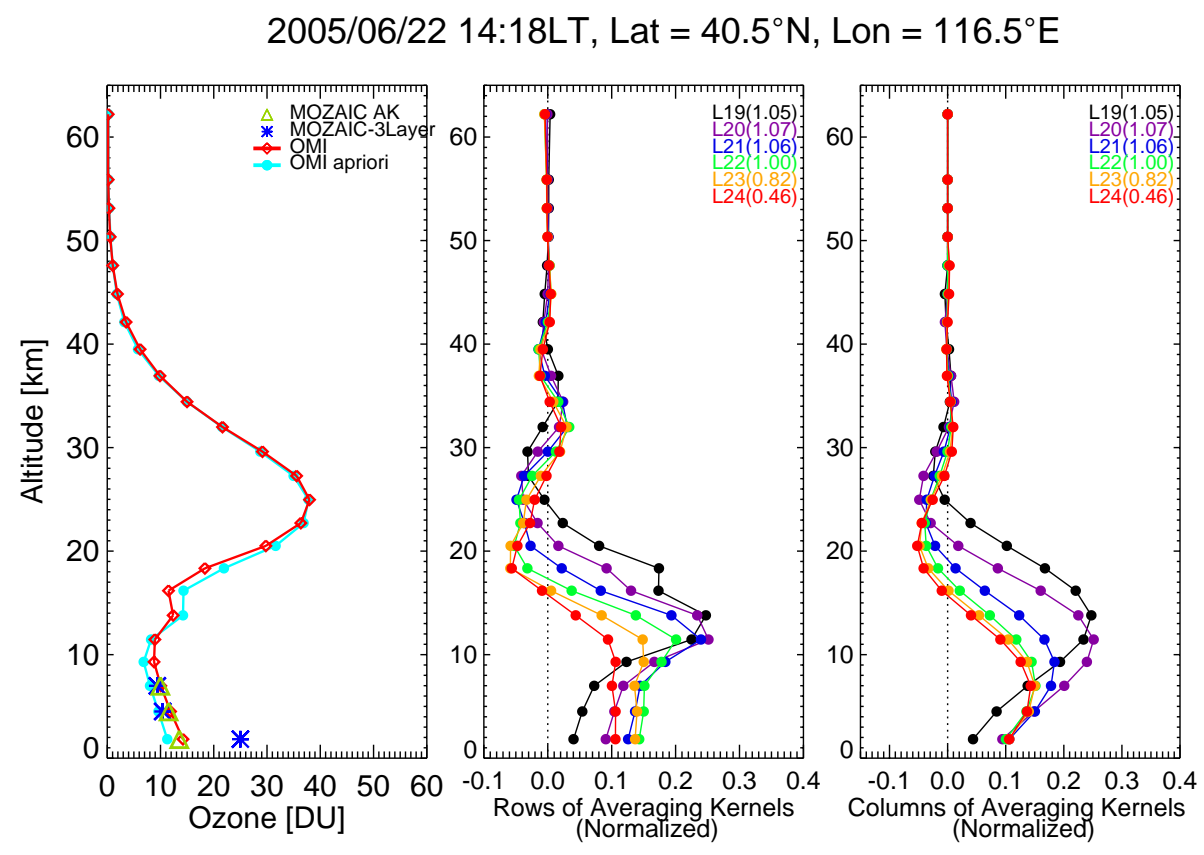

Figure 4. Ozone profile and AKs used for comparison for 22 June 2005. Latitude and longitude correspond to the OMI grid corresponding to the MOZAIC measurements. (Left) Solid blue line indicates the OMI a priori ozone profile; solid red line indicates the ozone profile derived from OMI spectra. Blue asterisks indicate MOZAIC ozone values adjusted to corresponding OMI layers. Light green triangles indicate MOZAIC ozone values convolved with the AKs shown in the middle panel. (Middle) Profiles of the rows of AKs normalized by the a priori error for the six layers of OMI retrieval. Black, violet, blue, green, yellow, and red lines correspond to the 19th, 20th, 21st, 22nd, 23rd, and 24th layers, respectively. The total retrieval efficiencies are shown in parentheses. (Right) Same as the middle panel but for the columns of the AKs normalized by the a priori error.

randomly about the zero point for the 22nd and 23rd layers. In the rightmost panels of Fig. 3, the correlation between $X-X_{a}$ (MOZAIC) at the 24th layer and $\Delta \mathrm{O}_{3}(\mathrm{OMI})$ of the upper layers in panels (c1) and (c2) is more significant than that with the same layer as in panels (b1) and (b2), which indicates that the effect of enhancement of ozone at the 24th layer could propagate to the upper layers. In panel (c3), we also show the correlation between $X-X_{a}$ (MOZAIC) at the 24th layer and the summation of $\Delta \mathrm{O}_{3}$ (OMI) of the three layers from the 22nd layer through the 24th layer. The correlation is in a reasonable range when we consider the large smoothing errors.

The ozone profile algorithm has the capability to include monthly mean Global Ozone Chemistry Aerosol Radiation and Transport (GOCART) model fields of aerosols (profiles of six types of aerosols) in the radiative transfer simulation (Chin et al., 2002; Martin et al., 2003; Liu et al., 2005). However, the aerosol fields are not used in OMI retrievals (Liu et al., 2010a). Because the fitting of wavelength-dependent surface albedo parameters can partly account for the effects of aerosols owing to similar weighting functions, the retrievals are not very sensitive to the inclusion of aerosols (Liu et al., 2005). For example, for the OMI ozone profile retrieval in Figs. 2 and 4, the corresponding monthly mean GOCART tropospheric aerosol optical depth is 0.65 at $347 \mathrm{~nm}$ with a single scattering albedo of 0.9. Using the aerosol fields only results in a small change in the retrieval: the total ozone column increases by $\sim 0.4 \mathrm{DU}$ from 327.4 to $327.8 \mathrm{DU}$, the tropospheric ozone column increases by $\sim 1.0 \mathrm{DU}$ from 54.9 to $55.9 \mathrm{DU}$, and the ozone in layer 24 decreases by $\sim 0.3 \mathrm{DU}$ from 15.6 to $15.3 \mathrm{DU}$. Therefore, the observed ozone enhancement shown in Figs. 2 and 4 is not caused by neglecting aerosols in the retrieval.

To confirm the consistency in the OMI ozone retrievals, we applied OMI AKs (rows) to the MOZAIC data by using the following equation:

$$
\begin{aligned}
& X_{j}^{\prime}=X_{a, j}+\sum_{i=1}^{n} A(i, j)\left[X_{t, i} X_{a, i}\right] X_{j}^{\prime} \\
& =X_{a, j}+\sum_{i=1}^{n} A(i, j)\left[X_{t, i}-X_{a, i}\right],
\end{aligned}
$$

where $X_{j}^{\prime}$ is the MOZAIC ozone profile convolved with the retrieval AKs $(A(i, j)), X_{t}$ is the MOZAIC ozone profile on the OMI altitude grid, and $X_{a}$ is the a priori profile used in the OMI retrievals. Here, $n=24$, and $j=24$ for the 24th layer of the OMI ozone. We applied Eq. (1) to MOZAIC measurements only for $i=22,23$, and 24, and we assumed $X_{t}$ as the OMI-retrieved data for the other layers above $(i=1,21)$ because of the unavailability of measurement data. The ozone 

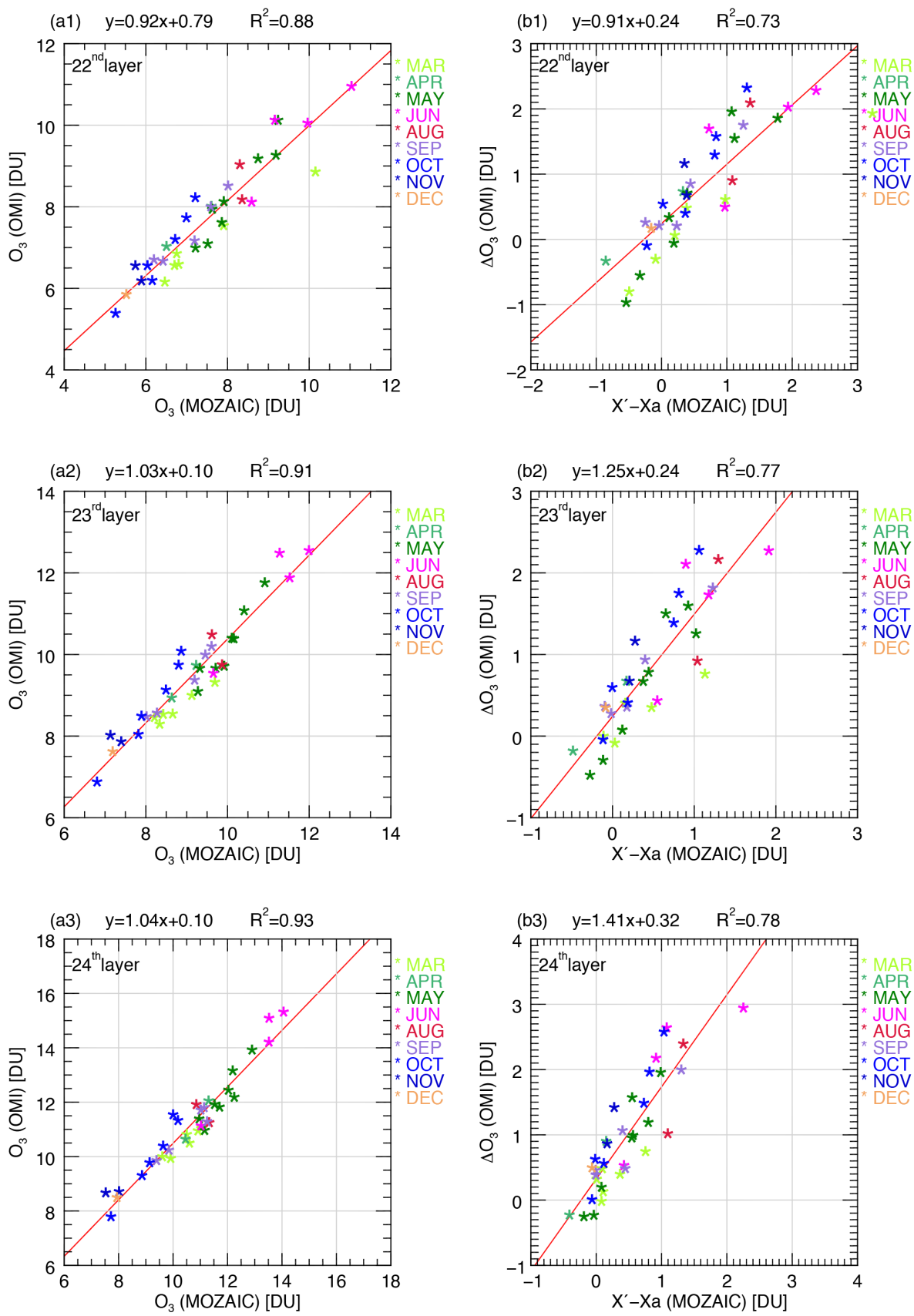

Figure 5. Same as Fig. 3a1-b3 except that MOZAIC values are convolved with OMI AKs (rows) according to Eq. (1).

values $\left(X_{t}\right)$ on 22 June 2005 are shown in the left panel of Fig. 4. Although the OMI-retrieved data do not represent the real ozone profile, it is the best estimate that we have. OMI ozone profiles have been shown to agree very well with collocated Microwave Limb Sounder (MLS) stratospheric $\mathrm{O}_{3}$ data (Liu et al., 2010b). Testing with ozonesonde data at latitudes $30-50^{\circ} \mathrm{N}$ shows that using OMI retrievals above layer 22 provides good and much better approximation of the real measurements to account for smoothing from upper layers to lower layers than using a priori values (not shown)
After applying Eq. (1), we compared the MOZAIC and OMI-retrieved ozone for the 22nd, 23rd, and 24th layers for the 36 days, as in Fig. 3. The left three panels of Fig. 5 (a1, a2, and a3) show the scatterplots of MOZAIC and OMI ozone retrievals. All data for the 36 days are color coded in the figure according to month, similar to those in Fig. 3. The values of the vertical axis (OMI-retrieved ozone) in Fig. 5 are the same as those in Fig. 3. As previously mentioned for Fig. 3, the strong correlation found in the panels of Fig. 3a is partly due to the retrieved ozone variation accompanied by the seasonal 
Table 1. List of the data used for comparison of MOZAIC and OMI.

\begin{tabular}{lll}
\hline & Date & Time of MOZAIC \\
No. & (yyyymmdd) & measurements (LT) \\
\hline 1 & 20041014 & $12: 48$ \\
2 & 20041024 & $12: 52$ \\
3 & 20041115 & $13: 57$ \\
4 & 20041210 & $14: 20$ \\
5 & 20050304 & $13: 58$ \\
6 & 20050309 & $14: 01$ \\
7 & 20050311 & $14: 06$ \\
8 & 20050318 & $13: 57$ \\
9 & 20050325 & $14: 02$ \\
10 & 20050329 & $11: 40$ \\
11 & 20050403 & $10: 38$ \\
12 & 20050428 & $10: 52$ \\
13 & 20050501 & $10: 28$ \\
14 & 20050503 & $10: 30$ \\
15 & 20050508 & $10: 25$ \\
16 & 20050511 & $13: 46$ \\
17 & 20050512 & $13: 54$ \\
18 & 20050515 & $10: 31$ \\
19 & 20050518 & $13: 50$ \\
20 & 20050524 & $10: 35$ \\
21 & 20050610 & $13: 53$ \\
22 & 20050615 & $14: 17$ \\
23 & 20050622 & $14: 18$ \\
24 & 20050623 & $11: 09$ \\
25 & 20050819 & $14: 11$ \\
26 & 20050821 & $10: 41$ \\
27 & 20050904 & $10: 42$ \\
28 & 20050906 & $10: 51$ \\
29 & 20050914 & $14: 03$ \\
30 & 20050918 & $10: 57$ \\
31 & 20050921 & $14: 04$ \\
32 & 20051005 & $13: 46$ \\
33 & 20051019 & $13: 59$ \\
34 & 20051026 & $13: 58$ \\
35 & 20051030 & $14: 28$ \\
36 & 20051111 & $14: 18$ \\
\hline & &
\end{tabular}

variation involved in the a priori values. Then, we again compared $\Delta \mathrm{O}_{3}$ with MOZAIC in Fig. $5 \mathrm{~b}$ in a similar fashion to Fig. 3. The right panels in Fig. 5 (b1, b2, and b3) show scatterplots of $X^{\prime}-X_{a}$ derived from MOZAIC measurements and $\Delta \mathrm{O}_{3}$ from OMI data after convolution in Eq. (1). The correlation of $X^{\prime}-X_{a}$ with $\Delta \mathrm{O}_{3}$ shown in Fig. $5 \mathrm{~b}$ was evaluated to be sufficiently close to unity with $R^{2}$ values of $\sim 0.75$. According to the testing with ozonesonde data, the use of OMI retrievals above layer 22 rather than real MOZAIC data will slightly overestimate the correlation from $R^{2}$ values of $\sim 0.60$. The slopes are also much closer to unity when compared to Fig. 3, although with slight overestimation by the OMI in the 23rd and 24th layers (1.25 and 1.41, respectively), which can be partly due to the use of OMI retrievals above layer 22. The results shown in Fig. 5 demonstrate the general consistency between OMI retrievals and the OMI retrieval scheme as approximated by Eq. (1) and the retrieval AKs. As seen from the difference between Figs. 3 and 5, it is obvious that OMI-retrieved values in the 22nd and 23rd layers in Fig. 3 (b1 and b2) are not correlated with MOZAIC data at all ( $R^{2}$ is almost zero). It means the OMI-retrieved ozone value at a certain layer does not necessarily represent the actual ozone value at the corresponding layer, but it is affected by the ozone values at different layers as mentioned for Fig. 4. In Fig. 5 we find much better correlation than in Fig. 3 after smoothing by AKs, which ensures that the OMI retrieval process is functioning self-consistently.

\subsection{Global distribution of $\Delta \mathrm{O}_{3}$ : effects of stratospheric ozone intrusion}

In the previous section, we demonstrated the validity of OMI retrievals and discussed uncertainties. In this section, we show an unusual ozone enhancement over CEC as compared with other areas. Figure 6 shows global maps of OMI $\Delta \mathrm{O}_{3}$ observed on 22 June 2005. Panels 1, 2, and 3 depict the 22nd, 23rd, and 24th layers, respectively. Because the AKs are based on the DU of the ozone amount, we divided the original ozone amount in DU by the layer thickness; thus, all data in Fig. 6 are in DU km${ }^{-1}$. If we present these figures in mixing ratios, $\mathrm{O}_{3}$ appears higher in the upper layers than in the lower layers. This result can provide a misleading interpretation, because air density is significantly lower in the upper layers. In fact, the absolute ozone amount is higher in the lower troposphere even if the mixing ratio is lower.

From Fig. 6, it is obvious that the high values of $\Delta \mathrm{O}_{3}$ are remarkable only over CEC, with the exception of the Arabian Peninsula near Qatar and tropical Africa. There was no systematic distribution of high $\Delta \mathrm{O}_{3}$ in the same latitudinal regions in which the solar zenith angle was similar, which demonstrates that the enhancement of ozone is not an apparent phenomenon due to the change in retrieval efficiency depending on solar zenith angle. The screening process according to the criteria of ECF and RMS, as described in Sect. 2, resulted in an absence of data in some areas.

The OMI 22nd layer was lower than $9 \mathrm{~km}$ and often lower than $\sim 8 \mathrm{~km}$ (Fig. 2); the layer was significantly lower than the tropopause, particularly in summer. Therefore, the OMI tropospheric ozone retrieved at layers 22-24 was significantly lower in altitude than the tropopause. Nevertheless, as mentioned in Sect. 1, awareness of stratospheric ozone intrusion is needed because ozone enhancement in the upper troposphere/lower stratosphere affects lower tropospheric ozone retrieval. Despite the difficulty in distinguishing ozone in the first three layers based on the rows of AKs (middle panel of Fig. 4), the columns of AKs (or the retrieval efficiency, right panel of Fig. 4) provide useful information about the likely source of ozone enhancement. As shown in Fig. 4, the retrieval efficiency curve for actual ozone enhancement in the lowermost layer tends to peak at layer 22 or 



Figure 6. Global maps of $\Delta \mathrm{O}_{3}$ observed by OMI at the (1) 22nd, (2) 23rd, and (3) 24th layers on 22 June 2005, which correspond to the MOZAIC measurement shown in Fig. 2. The unit of ozone amount is noted by DU km${ }^{-1}$. Cloudy areas were screened out with the criteria of ECF $<0.2$ and data quality as RMS $<2.4$ (shown in white).

lower, whereas the curve for actual ozone enhancement from stratospheric intrusion tends to peak at higher altitudes (e.g., layers 19 and 20). Therefore, the peak layer of ozone retrieval enhancement can help to discriminate between stratospheric intrusion and the lowermost troposphere as the source of ozone enhancement, especially when there is significant tropospheric ozone enhancement. Figure 7 shows the peak layer of $\Delta \mathrm{O}_{3}$, hereafter referred to as the layer peak, for all nearly clear-sky grids in which the $\Delta \mathrm{O}_{3}$ for TCO was larger than $0.8 \mathrm{DU} \mathrm{km}^{-1}$ on 22 June 2005. Over China, the peak layer was at layer 24 , suggesting that the ozone enhancement was probably from the lowermost troposphere.
In Fig. 8, we show a global map of NCEP wind at $200 \mathrm{hPa}$ on the same day, with the location of the maximum wind speed indicating an STJ that is closely related to the stratospheric ozone intrusion (e.g., Holton et al., 1995). In contrast to the case over CEC, the peak layer over the eastern Pacific occurred predominantly in layers $19-20$ (about $12-15 \mathrm{~km}$ in altitude), suggesting the stratosphere as a likely origin, as confirmed by the location of the STJ shown in Fig. 8. We visualized all OMI data in Fig. 6 with NCEP wind data in Fig. 8 during the entire observation period from 2004 to 2013, and we surveyed all of the data (figure not shown). With this visual examination, we found no correlation between $\Delta \mathrm{O}_{3}$ in the 24th layer and the location of the subtropical jet. 


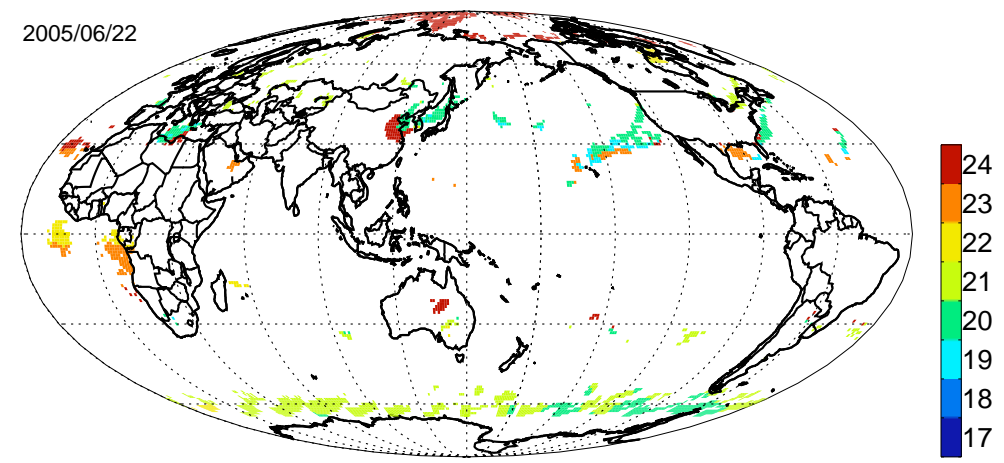

Figure 7. The layer peak for the ozone enhancement $\left(\Delta \mathrm{O}_{3}\right)$ on 22 June 2005. Grids were selected where the TCO was larger than $0.8 \mathrm{DU} \mathrm{km}^{-1}$.

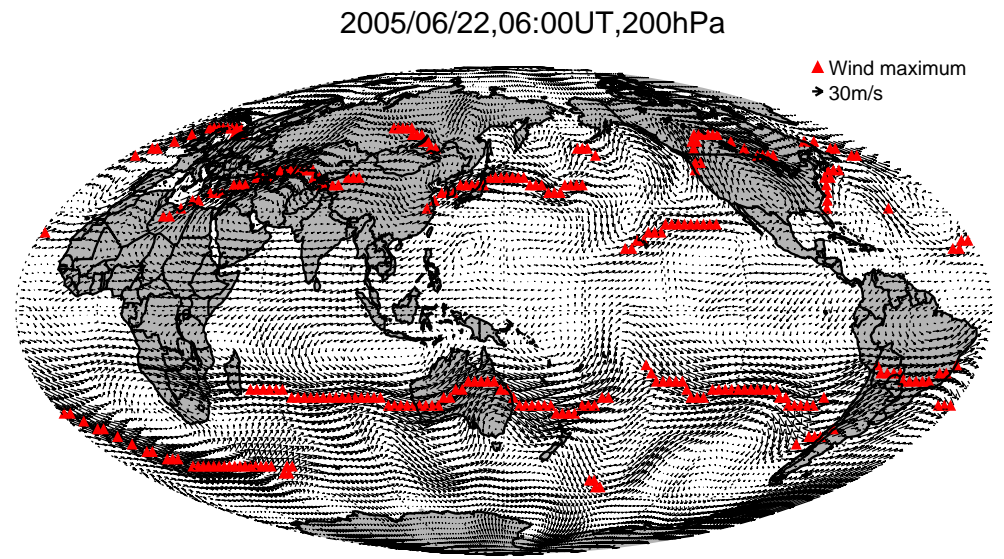

Figure 8. A global map of NCEP wind at $200 \mathrm{hPa}$ at 06:00 UT (14:00 CST). Locations of maximum wind speed along the longitude are denoted by red triangles.

\subsection{Annual and inter-annual variation of ozone distribution in the lower troposphere}

Figure 9 shows the monthly mean value of the OMI-retrieved ozone from January to December 2005 at the 24th layer. It should be noted that the monthly mean map shown in Fig. 9 is not synoptic; rather, it is a composite of patchy measurements made under clear-sky conditions only. However, more than half $(>15)$ of the data were generally available in most of the areas; the data numbers are shown in the Supplement (Fig. S2). Figure 9 shows obvious ozone enhancement in the lower troposphere in June. The layer peak data were also investigated in June 2005. The most frequent layer peak in June 2005 occurred in the 24th layer over CEC. This result supports the finding that the ozone enhancement observed in June, other than the typical example day of 22 June, can be attributed to the lower troposphere and not to the upper troposphere.

Figure 10 shows the monthly mean value of the retrieved ozone at the 24th layer in June from 2005 through 2013. The year-to-year variability is significant; however, the spatial distribution pattern is similar every year, whereby a region of high ozone concentration appears around the Shandong Peninsula. The maps after 2009 had relatively noisy features due to inferior data quality and reduced spatial coverage after the severe row anomaly problem in 2009 . However, despite some noisy patterns shown in the maps after 2009, the characteristic feature of ozone enhancement can be recognized every year. The data numbers shown in the supplementary files (Fig. S3) reveal that most of the grids are covered by more than 15 data.

In CEC, an unusually high rate of ozone production could be attributed to emissions of anthropogenic ozone precursors such as $\mathrm{NO}_{x}, \mathrm{CO}$, and VOCs. High concentrations of $\mathrm{NO}_{x}$ in CEC are well known from satellite measurements (e.g., Richter et al., 2005). In addition to those from emissions of industrial activities and automobile exhaust, recent studies revealed significant effects on ozone production by emissions derived from agricultural activities in June, especially OCRB after the harvesting of winter wheat. Fu et al. (2007) used a 6-year record (1996 to 2001) of GOME satellite HCHO measurements and investigated regional emissions over South Asia and East Asia. They revealed a large source to be agri- 


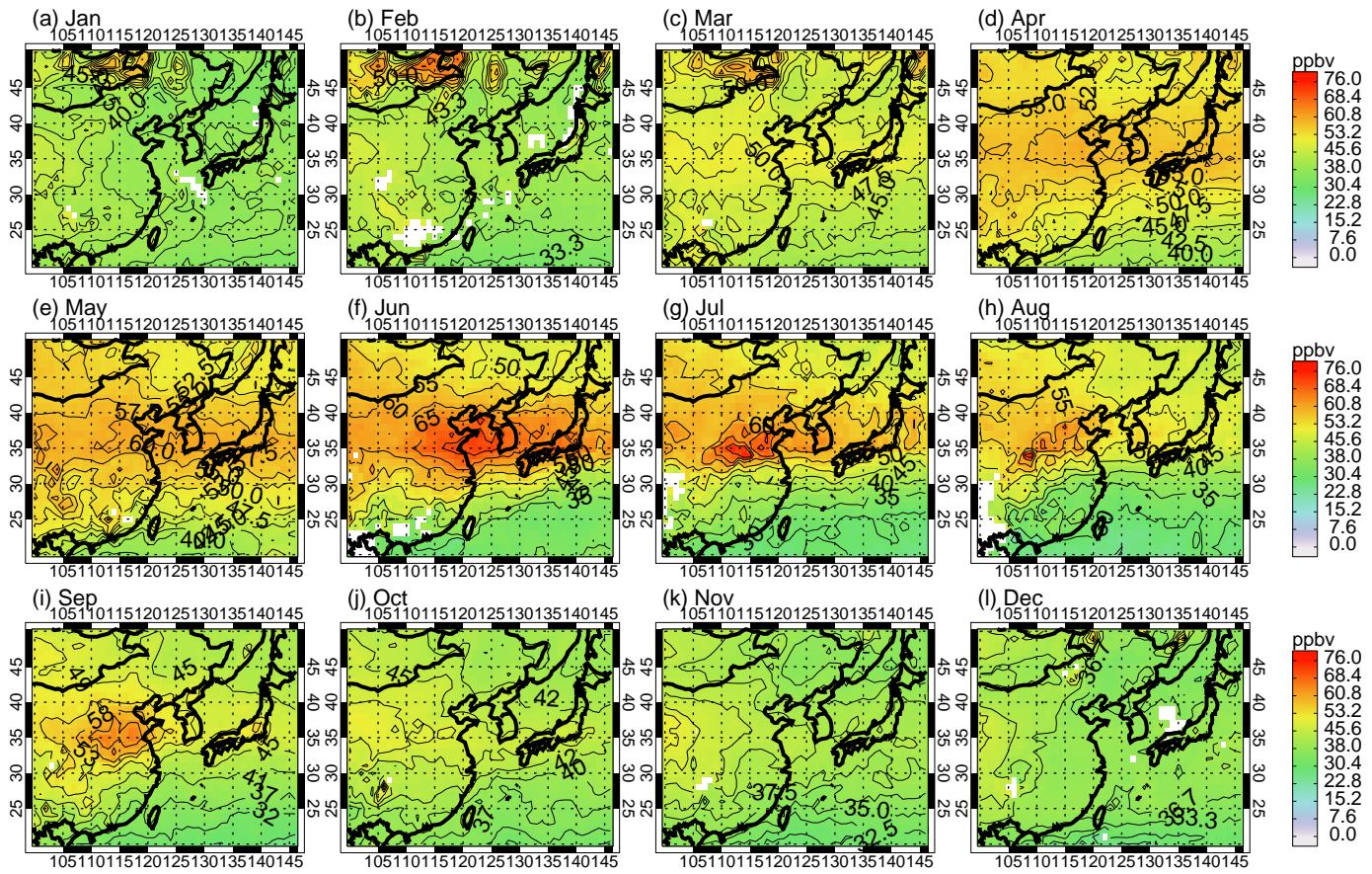

Figure 9. Maps of monthly mean values of retrieved ozone at the 24th layer from January to December 2005.

(a)2005

(b)2006

(c) 2007


(d) 2008

(e)2009

(f) 2010
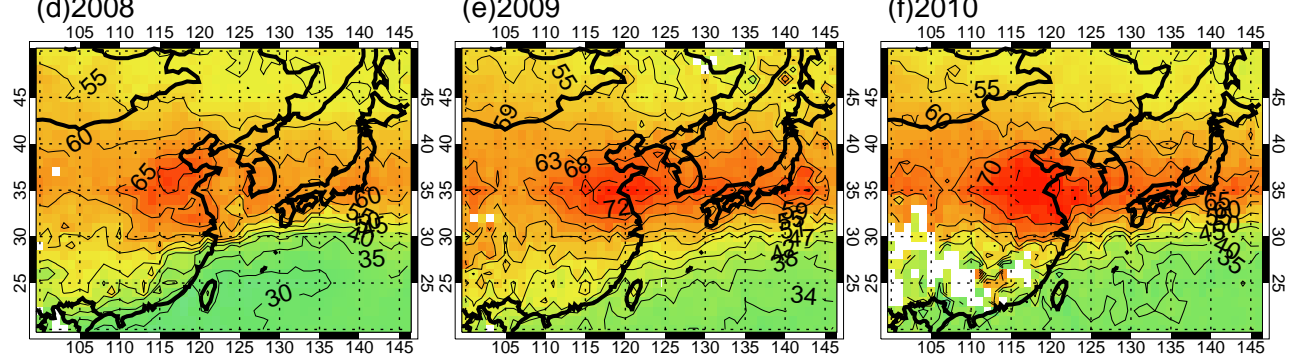

\begin{tabular}{|l|} 
ppbv \\
\hline 76.0 \\
68.4 \\
60.8 \\
53.2 \\
45.6 \\
38.0 \\
30.4 \\
22.8 \\
15.2 \\
7.6 \\
0.0 \\
\hline
\end{tabular}

(g)2011

(h)2012

(i) 2013
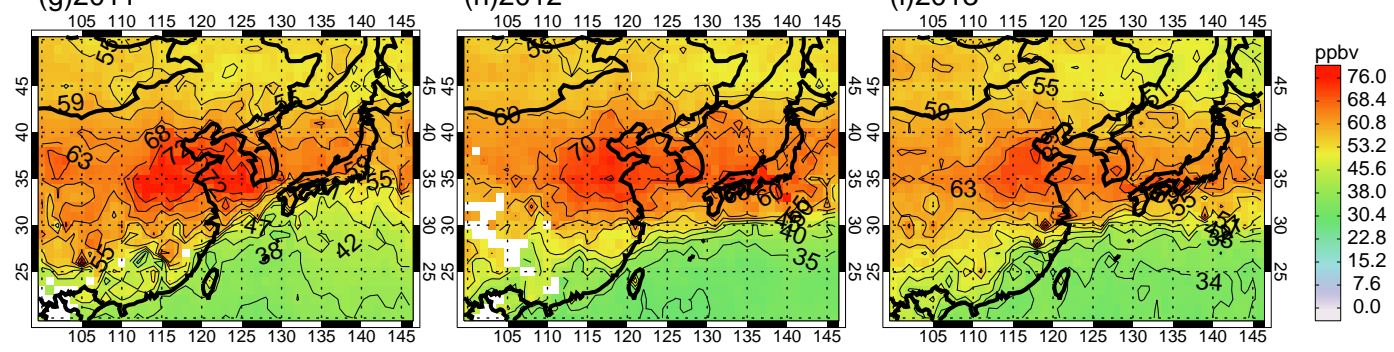

Figure 10. Maps of monthly mean values of retrieved ozone at the 24th layer in June from 2005 to 2013. 

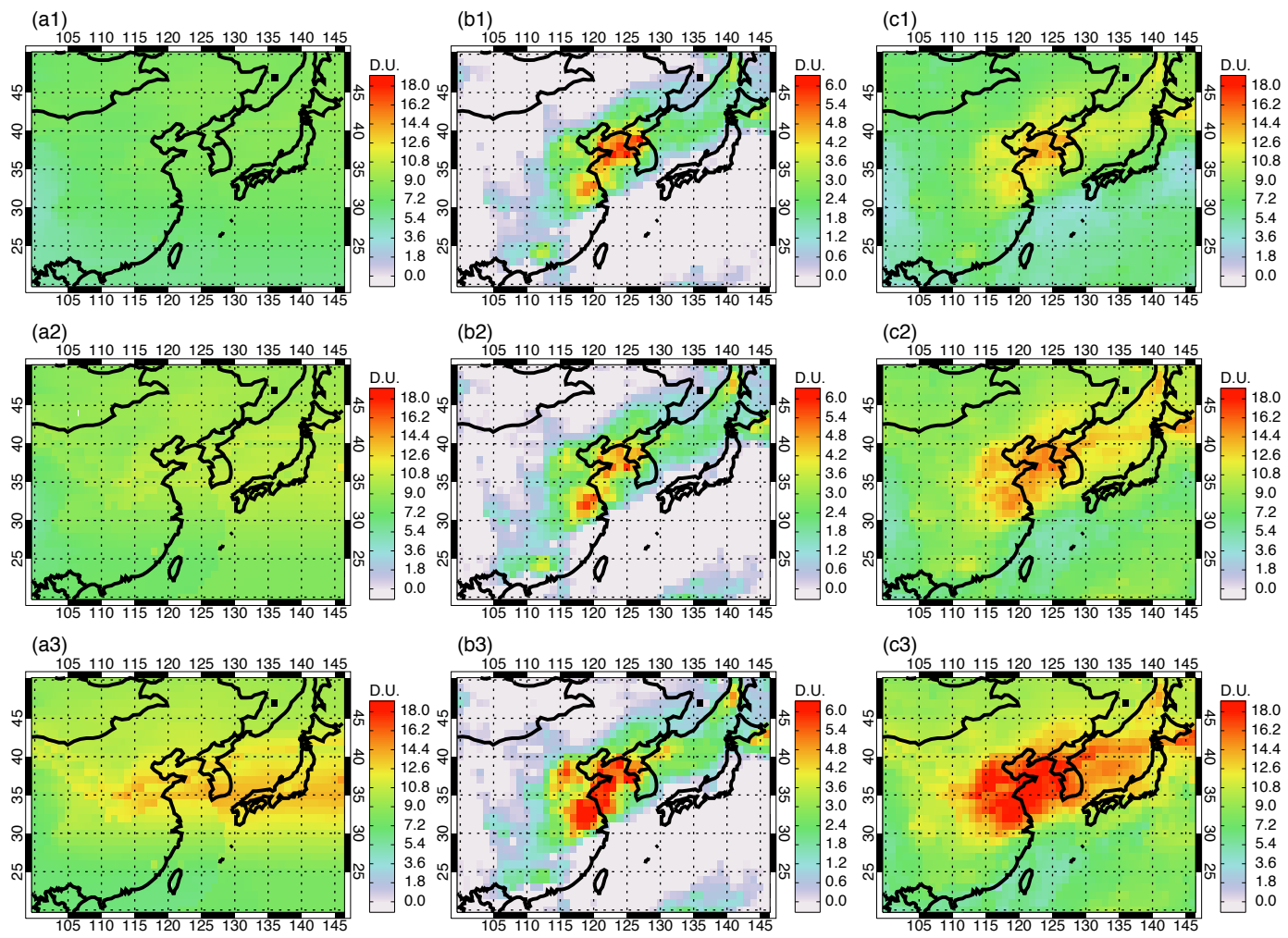

Figure 11. Maps of (a) a priori ozone, (b) OMI-derived $\Delta \mathrm{O}_{3}$, and (c) OMI-derived $\mathrm{O}_{3}$ on 22 June 2005. 1, 2, and 3 represent the 22nd, 23rd, and 24 th layers, respectively.

cultural burning in the North China Plain in June, which is not included in current bottom-up inventories.

In Fig. 11, we show East Asian maps of the a priori values, $\Delta \mathrm{O}_{3}$, and retrieved ozone observed by $\mathrm{OMI}$ in the 22nd layer, 23rd layer, and 24th layer on 22 June 2005. The ozone enhancement was clearly visible over Shandong and the North China Plain. For comparison with lower tropospheric ozone enhancements, we also show in Fig. 12a and c the CO distribution observed from MOPITT and the hotspot numbers taken from MODIS obtained on the same day, respectively. The areas in which significant hotspots were found correspond to $\mathrm{CO}$ and ozone enhancements. This result obtained from OMI is consistent with that in the previous studies of MTX2006 that investigated the effect of OCRB on ozone production. The results shown in Fig. 9f are comparable with those in Fig. 12b and d, and the region of ozone enhancement is also strongly connected to $\mathrm{CO}$ and hotspots on a monthly basis.

\section{Suggestions for future study}

Ozone enhancement was most notable in June of every year, as presented in Fig. 9. Some model studies were published in the MTX2006 special issue. Li et al. (2008) used a 3-D regional chemical transport model, known as the Nested Air
Quality Model System (NAQPMS). They presented the simulated monthly mean near-ground ozone (Fig. 5 of Li et al., 2008). The geographical distribution of ozone was comparable to that in Fig. 10b in the present study. The comparison of OMI-derived ozone maps with multiple-mode simulations can lead to a better understanding of emissions from crop burning, which is an important topic for further investigation.

The ozone maps shown in Figs. 9 and 10 indicate that the maximum $\Delta \mathrm{O}_{3}$ value diminished gradually downstream of CEC, suggesting an outflow of ozone plumes from China to South Korea and Japan. Detailed meteorological analysis to reveal the transport processes of ozone as investigated by Pan et al. (2013) is currently under study, coupled with the analysis of the ground-based data over Japan taken from the database of the Atmospheric Environmental Regional Observation System (AEROS; http://soramame.taiki.go.jp/). As previously mentioned, it would be difficult to reveal the ozone distribution in East Asia by only the use of groundbased monitoring stations and sea-borne measurements. In this study, we demonstrated the potential of satellite measurements to address this issue. The ozone maps shown in Figs. 9 and 10 will be helpful for modelers in examining the effects of various emission scenarios on ozone production and for exploring unknown factors influencing ozone distribution. 
(a)

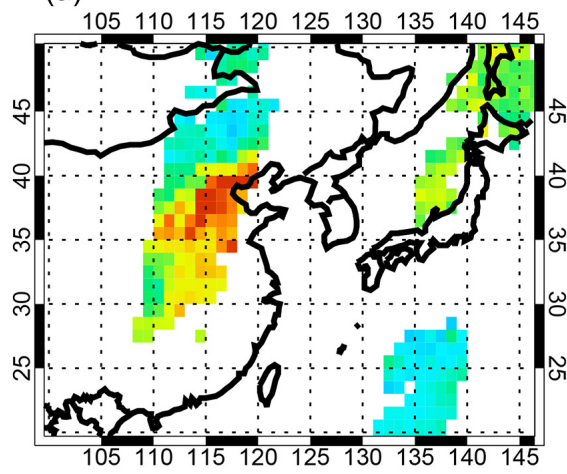

(b) (c)

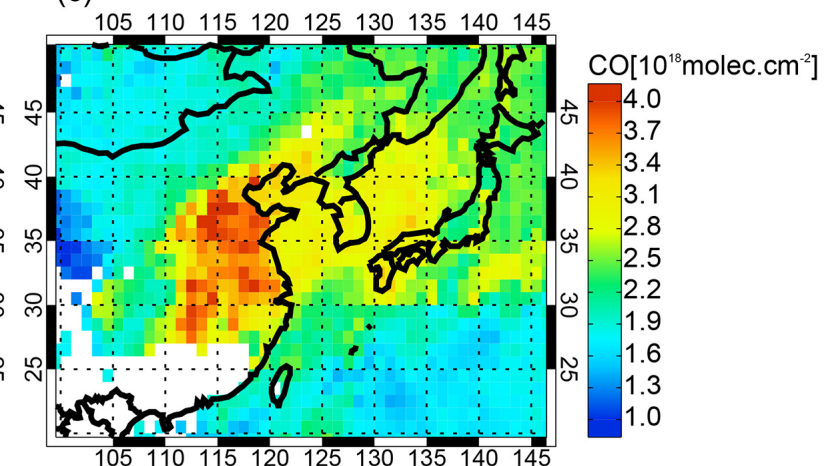

(d)
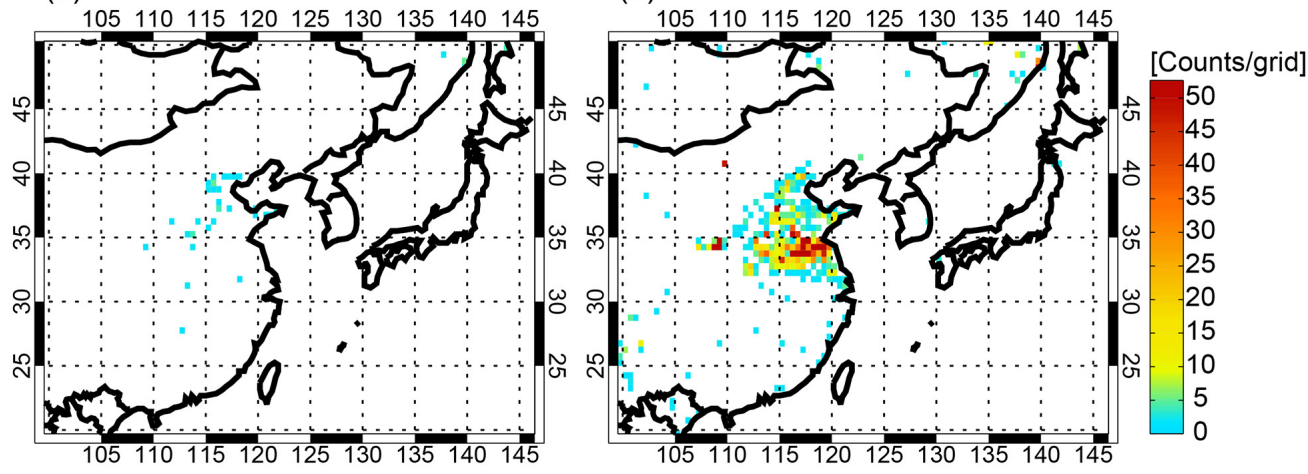

Figure 12. Maps of (a) CO in column number density observed by MOPITT and (b) hotspot numbers taken from MODIS on 22 June 2005 for $0.5^{\circ} \times 0.5^{\circ}$ grids in latitude and longitude. (c) As for (a) but for the monthly average of June 2005. (d) As for (b) but for the monthly accumulation in June 2005.

As discussed in Sect. 3.1.4, UV radiation measurements are sensitive to ozone in the lowermost altitudes, although this sensitivity is not sufficiently large. However, validation for the lowermost altitude has not been sufficiently studied. The validation under conditions of significantly enhanced ozone, such as those observed over CEC, has not been performed prior to this study because only limited ozone profile data over China are available. Further research on validation using ozonesonde data and other possible in situ measurements is necessary to utilize the OMI retrieval for quantitative analyses.

A prospective synergetic retrieval algorithm combining UV and TIR should be the subject of future study. Cuesta et al. (2013) applied a multispectral synergetic algorithm with IASI for TIR and GOME-2 for UV radiation. It may be possible to extend their algorithm to couple with the OMI retrievals shown in the present study. Combined use of OMI and TES, both of which are based on the same platform, and the EOS Aura satellite would also be highly useful, as Fu et al. (2013) demonstrated in their feasibility study. We hope this research will encourage such a synergetic study.

\section{Summary}

The recent OMI products retrieved by Liu et al. (2010a) revealed spatial and temporal variations in ozone distributions in multiple tropospheric layers. The validation of OMI ozone retrieval for the lowermost troposphere under the conditions of significantly enhanced ozone, such as those observed over CEC, has not been evaluated prior to this study because only limited ozone profile data over China are available. We compared the OMI-derived ozone over Beijing with airborne measurements conducted by the MOZAIC program, and we examined in detail the possibility of lower tropospheric ozone detection from OMI over Beijing, although the data were limited to the period before November 2005. Under the condition of highly enhanced ozone such as that over Beijing, the correlation between OMI and MOZAIC ozone in the lower troposphere was reasonable, which verified the reliability of OMI ozone retrievals at the lower troposphere under enhanced ozone conditions. The ozone enhancement over CEC was clear in June of every year. This result suggests the possibility that a considerable portion of the enhancement could be attributed to the emissions of ozone precursors from residue burning after the harvesting of winter wheat in these regions, as investigated by in situ measurements in MTX2006 (Kanaya et al., 2013). 
The lower tropospheric ozone distribution maps were first obtained from OMI retrieval in the present study; these maps are consistent with the results from some model simulations. The OMI-derived information on lower tropospheric ozone will be helpful for the investigation of as yet unknown factors influencing ozone distribution by comparison with model simulations. Such a topic is intended for future study.

\section{The Supplement related to this article is available online at doi:10.5194/acp-15-9865-2015-supplement.}

Acknowledgements. We express our thanks to the European Commission for the support to the MOZAIC project (1994-2003), to partner institutions of the IAGOS Research Infrastructure (FZJ, DLR, MPI, and KIT in Germany; CNRS, CNES, and MétéoFrance in France; and the University of Manchester in the United Kingdom), ETHER (CNES-CNRS/INSU) for hosting the database, and to participating airlines (Lufthansa, Air France, Austrian, China Airlines, Iberia, and Cathay Pacific) for transporting the instrumentation free of charge. We also express our gratitude to H. Araki and M. Nakazawa for their help with the data analysis and creation of figures, and to Yugo Kanaya for his helpful comments on MTX2006. S. Hayashida and A. Ono were supported by a Grant-in-Aid from the Green Network of Excellence, Environmental Information (GRENE-ei) program, MEXT, Japan. X. Liu and K. Chance were supported by NASA and the Smithsonian Institution.

Edited by: M. Van Roozendael

\section{References}

Bhartia, P. K., McPeters, R. D., Mateer, C. L., Flynn, L. E., and Wellemeyer, C.: Algorithm for the estimation of vertical ozone profiles from the backscattered ultraviolet technique, J. Geophys. Res., 101, 18793-18806, 1996.

Chance, K. V., Burrows, J. P., Perner, D., and Schneider, W.: Satellite measurements of atmospheric ozone profiles, including tropospheric ozone, from ultraviolet/visible measurements in the nadir geometry: A potential method to retrieve tropospheric ozone, J. Quant. Spectrosc. Radiat. Transfer, 57, 467-476, 1997.

Chance, K. V., Palmer, P. I., Spurr, R. J. D., Martin, R. V., Kurosu, T., and Jacob, D. J.: Satellite observations of formaldehyde over North America from GOME, Geophy. Res. Lett., 27, 3461-3464, 2000

Chin, M., Ginoux, P., Kinne, S., Torres, O., Holben, B. N., Duncan, B. N., Martin, R. V., Logan, J. A., Higurashi, A., and Nakajima, T.: Tropospheric aerosol optical thickness from the GOCART model and comparisons with satellite and sunphotometer measurements, J. Atmos. Sci., 59, 461- 483, 2002.

Cuesta, J., Eremenko, M., Liu, X., Dufour, G., Cai, Z., Höpfner, M., von Clarmann, T., Sellitto, P., Foret, G., Gaubert, B., Beekmann, M., Orphal, J., Chance, K., Spurr, R., and Flaud, J. M.:
Satellite observation of lowermost tropospheric ozone by multispectral synergism of IASI thermal infrared and GOME-2 ultraviolet measurements over Europe, Atmos. Chem. Phys., 13, 9675-9693, doi:10.5194/acp-13-9675-2013, 2013.

Deeter, M. N., Worden, H. M., Gille, J. C., Edwards, D. P., Mao, D., and Drummond, J. R.: MOPITT multispectral CO retrievals: Origins and effects of geophysical radiance errors, J. Geophys. Res., 116, D15303, 2011.

Deeter, M. N., Martínez-Alonso, S., Edwards, D. P., Emmons, L. K., Gille, J. C., Worden, H. M., Pittman, J. V., Daube, B. C., and Wofsy, S. C.: Validation of MOPITT Version 5 thermalinfrared, near-infrared, and multispectral carbon monoxide profile retrievals for 2000-2011, J. Geophys. Res. Atmos., 118, 6710-6725, 2013.

Ding, A. J., Fu, C. B., Yang, X. Q., Sun, J. N., Zheng, L. F., Xie, Y. N., Herrmann, E., Nie, W., Petäjä, T., Kerminen, V. M., and Kulmala, M.: Ozone and fine particle in the western Yangtze River Delta: An overview of 1yr data at the SORPES station, Atmos. Chem. Phys., 13, 5813-5830, doi:10.5194/acp-13-58132013, 2013.

European Organisation for the Exploitation of Meteorological Satellites (EUMETSAT): GOME-2 Level 1 product generation specification, EPS.SYS.SPE.990011, Darmstadt, Germany, 2006.

Fishman, J. and Larsen, J. C.: Distribution of total ozone and stratospheric ozone in the tropics' implications for the distribution of tropospheric ozone, J. Geophys. Res., 92, 6627-6634, 1987.

Fishman, J., Wozniak, A. E., and Creilson, J. K.: Global distribution of tropospheric ozone from satellite measurements using the empirically corrected tropospheric ozone residual technique: Identification of the regional aspects of air pollution, Atmos. Chem. Phys., 3, 893-907, doi:10.5194/acp-3-893-2003, 2003.

Fu, D., Worden, J. R., Liu, X., Kulawik, S. S., Bowman, K. W., and Natraj, V.: Characterization of ozone profiles derived from aura TES and OMI radiances, Atmos. Chem. Phys., 13, 3445-3462, doi:10.5194/acp-13-3445-2013, 2013.

Fu, T.-M., Jacob, D. J., Palmer, P. I., Chance, K., Wang, Y. X., Barletta, B., Blake, D. R., Stanton, J. C., and Pilling, M. J.: Space-based formaldehyde measurements as constraints on volatile organic compound emissions in east and south Asia and implications for ozone, J. Geophys. Res., 112, D06312, doi:10.1029/2006JD007853, 2007.

Giglio, L., Descloitres, J., Justice, C. O., and Kaufman, Y. J.: An enhanced contextual fire detection algorithm for MODIS, Remote Sens. Environ, 87, 273-282, 2003.

Gottwald, M. and Bovensmann, H.: SCIAMACHY-Exploring the changing Earth's atmosphere, Springer, Germany, 2011.

Hayashida, S., Urita, N., Noguchi, K., Liu, X., and Chance, K.: Spatiotemporal variation in tropospheric column ozone over East Asia observed by GOME and ozonesondes, SOLA, 4, 117-120, doi:10.2151/sola.2008-030, 2008.

Holton, J. R., Haynes, P. H., McIntyre, M. E., Douglass, A. R., Rood, R. B., and Pfister, L.: Stratosphere-troposphere exchange, Rev. Geophys., 33, 403, doi:10.1029/95rg02097, 1995.

IPCC: Climate Change 2007: The Physical Scientific Basis, Contribution of Working Group I to the Fourth Assessment Report of the Intergovernmental Panel on Climate Change, edited by: Solomon, S., Qin, D., Manning, M., Chen, Z., Marquis, M., Averyt, K. B., Tignor, M., and Miller, H. L., Cambridge University 
Press, Cambridge, United Kingdom and New York, NY, USA, 2007.

Justice, C. O., Giglio, L., Korontzi, S., Owens, J., Morisette, J. T., Roy, D., Descloitres, J., Alleaume, S., Petitcolin, F., and Kaufman, Y.: The MODIS fire products, Remote Sens. Environ., 83, 244-262, 2002.

Kanaya, Y., Akimoto, H., Wang, Z. F., Pochanart, P., Kawamura, K., Liu, Y., Li, J., Komazaki, Y., Irie, H., Pan, X. L., Taketani, F., Yamaji, K., Tanimoto, H., Inomata, S., Kato, S., Suthawaree, J., Okuzawa, K., Wang, G., Aggarwal, S. G., Fu, P. Q., Wang, T., Gao, J., Wang, Y., and Zhuang, G.: Overview of the Mount Tai Experiment (MTX2006) in Central East China in June 2006: Studies of significant regional air pollution, Atmos. Chem. Phys., 13, 8265-8283, doi:10.5194/acp-13-8265-2013, 2013.

Kar, J., Fishman, J., Creilson, J. K., Richter, A., Ziemke, J., and Chandra, S.: Are there urban signatures in the tropospheric ozone column products derived from satellite measurements?, Atmos. Chem. Phys., 10, 5213-5222, doi:10.5194/acp-10-5213-2010, 2010.

Kim, P. S., Jacob, D. J., Liu, X., Warner, J. X., Yang, K., Chance, K., Thouret, V., and Nedelec, P.: Global ozone - CO correlations from OMI and AIRS: Constraints on tropospheric ozone sources, Atmos. Chem. Phys., 13, 9321-9335, doi:10.5194/acp-13-93212013, 2013.

Landgraf, J. and Hasekamp, O. P.: Retrieval of tropospheric ozone: The synergistic use of thermal infrared emission and ultraviolet reflectivity measurements from space, J. Geophys. Res., 112, D08310, doi:10.1029/2006JD008097, 2007.

Levelt, P. F., van den Oord, G. H. J., Dobber, M. R., Malkki, A., Huib, V., Johan de, V., Stammes, P., Lundell, J. O. V., and Saari, H.: The Ozone Monitoring Instrument, IEEE T. Geosci. Remote, 44, 1093-1101, 2006.

Li, J., Wang, Z., Akimoto, H., Yamaji, K., Takigawa, M., Pochanart, P., Liu, Y., Tanimoto, H., and Kanaya, Y.: Nearground ozone source attributions and outflow in Central Eastern China during MTX2006, Atmos. Chem. Phys., 8, 7335-7351, doi:10.5194/acp-8-7335-2008, 2008.

Lin, W., Xu, X., Zhang, X., and Tang, J.: Contributions of pollutants from North China Plain to surface ozone at the Shangdianzi GAW station, Atmos. Chem. Phys., 8, 5889-5898, doi:10.5194/acp-8-5889-2008, 2008.

Liu, X., Chance, K., Sioris, C. E., Spurr, R. J. D., Kurosu, T. P., Martin, R. V., and Newchurch, M. J.: Ozone profile and tropospheric ozone retrievals from the global ozone monitoring experiment: Algorithm description and validation, J. Geophys. Res., 110, D20307, doi:10.1029/2005JD006240, 2005.

Liu, X., Bhartia, P. K., Chance, K., Spurr, R. J. D., and Kurosu, T. P.: Ozone profile retrievals from the Ozone Monitoring Instrument, Atmos. Chem. Phys., 10, 2521-2537, doi:10.5194/acp-10-25212010, 2010a.

Liu, X., Bhartia, P. K., Chance, K., Froidevaux, L., Spurr, R. J. D., and Kurosu, T. P.: Validation of Ozone Monitoring Instrument (OMI) ozone profiles and stratospheric ozone columns with Microwave Limb Sounder (MLS) measurements, Atmos. Chem. Phys., 10, 2539-2549, doi:10.5194/acp-10-2539-2010, 2010b.
Marenco, A., Thouret, V., Nedelec, P., Smit, H., Helton, M., Kley, D., Karcher, F., Simon, P., Law, K., Pyle, J., Poschmann, G., Wrede, R. V., Hume, C., and Cook, T.: Measurement of ozone and water vapor by Airbus in-service aircraft: The MOZAIC airborne program, An overview, J. Geophys. Res., 103, 2563125642, 1998.

Martin, R. V., Jacob, D. J., Yantosca, R. M., Chin, M., and Ginoux, P.: Global and regional decreases in tropospheric oxidants from photochemical effects of aerosols, J. Geophys. Res., 108, 4097, doi:10.1029/2002JD002622, 2003.

McPeters, R. D., Labow, G. J., and Logan, J. A.: Ozone climatological profiles for satellite retrieval algorithms, J. Geophys. Res., 112, D05308, doi:10.1029/2005jd006823, 2007.

Nakatani, A., Kondo, S., Hayashida, S., Nagashima, T., Sudo, K., Liu, X., Chance, K., and Hirota, I.: Enhanced mid-latitude tropospheric column ozone over East Asia: Coupled effects of stratospheric ozone intrusion and anthropogenic sources, J. Meteor. Soc. Jpn, 90, 207-222, 2012.

Natraj, V., Liu, X., Kulawik, S., Chance, K., Chatfield, R., Edwards, D. P., Eldering, A., Francis, G., Kurosu, T., Pickering, K., Spurr, R., and Worden, H.: Multi-spectral sensitivity studies for the retrieval of tropospheric and lowermost tropospheric ozone from simulated clear-sky geo-cape measurements, Atmos. Environ., 45, 7151-7165, 2011.

Ohara, T., Akimoto, H., Kurokawa, J., Horii, N., Yamaji, K., Yan, X., and Hayasaka, T.: An Asian emission inventory of anthropogenic emission sources for the period 1980-2020, Atmos. Chem. Phys., 7, 4419-4444, doi:10.5194/acp-7-4419-2007, 2007.

Pan, X. L., Kanaya, Y., Wang, Z. F., Komazaki, Y., Taketani, F., Akimoto, H., and Pochanart, P.: Variations of carbonaceous aerosols from open crop residue burning with transport and its implication to estimate their lifetimes, Atmos. Environ., 74, 301-310, 2013.

Richter, A., Burrows, J. P., Nuss, H., Granier, C., and Niemeier, U.: Increase in tropospheric nitrogen dioxide over China observed from space, Nature, 437, 129-132, 2005.

Rodgers, C. D.: Inverse methods for atmospheric sounding: Theory and practice, World Scientific Publishing, Singapore, 2000.

Streets, D. G., Bond, T. C., Carmichael, G. R., Fernandes, S. D., Fu, Q., He, D., Klimont, Z., Nelson, S. M., Tsai, N. Y., Wang, M. Q., Woo, J.-H., and Yarber, K. F.: An inventory of gaseous and primary aerosol emissions in Asia in the year 2000, J. Geophys. Res., 108, p. 8809, doi:10.1029/2002jd003093, 2003.

Wang, T., Ding, A., Gao, J., and Wu, W. S.: Strong ozone production in urban plumes from Beijing, China, Geophys. Res. Lett., 33, L21806, doi:10.1029/2006GL027689, 2006.

Worden, J., Liu, X., Bowman, K., Chance, K., Beer, R., Eldering, A., Gunson, M., and Worden, H.: Improved tropospheric ozone profile retrievals using OMI and TES radiances, Geophys. Res. Lett., 34, L01809, doi:10.1029/2006GL027806, 2007.

Yamaji, K., Li, J., Uno, I., Kanaya, Y., Irie, H., Takigawa, M., Komazaki, Y., Pochanart, P., Liu, Y., Tanimoto, H., Ohara, T., Yan, X., Wang, Z., and Akimoto, H.: Impact of open crop residual burning on air quality over Central Eastern China during the Mount Tai experiment 2006 (MTX2006), Atmos. Chem. Phys., 10, 7353-7368, doi:10.5194/acp-10-7353-2010, 2010. 